\title{
Rocket Internet: organizing a startup factory
}

\author{
Oliver Baumann ${ }^{1^{*}} \mathbb{D}$, Carsten Bergenholtz ${ }^{2}$, Lars Frederiksen², Robert M. Grant ${ }^{3}$, Rebecca Köhler ${ }^{4}$, \\ David L. Preston ${ }^{5}$ and Scott Shane ${ }^{6}$
}

* Correspondence: oliv@sod.dias.sdu.dk

${ }^{1}$ Department of Marketing \& Management, University of

Southern Denmark, Campusvej 55, 5230 Odense M, Denmark

Full list of author information is available at the end of the article

\begin{abstract}
While some firms build cars or smartphones, Rocket Internet builds companies. The incubator and investment firm has pioneered an extreme approach to new venture creation that is often referred to as a "startup factory:" it rapidly assembles and scales new companies, replicating business models that have been developed elsewhere. Separating the ideation of business models from their execution allows Rocket Internet to specialize on the latter, because it eliminates the need to create an environment that is conducive to both processes. Yet specialization may also be Rocket Internet's largest liability, because it makes the firm dependent on the availability of appropriate (cospecialized) business models. In this edition of the Organization Zoo series, we asked several organizational scientists and scholars of entrepreneurship to share their thoughts on what we can learn from the case of Rocket Internet.
\end{abstract}

Keywords: Organization design, Incubator, Company builder, Business model replication, Imitation, New venture creation

\section{Introduction}

\section{Oliver Baumann and Rebecca Köhler}

While some firms build cars or smartphones, Rocket Internet builds companies. The incubator and investment firm has pioneered an extreme approach to new venture creation that is often referred to as a "startup factory." Following its mission "to become the world's largest Internet platform outside the United States and China," Rocket Internet creates and grows new ventures by aggressive replication of Internet-based business models that have been developed elsewhere.

Rocket Internet was established in 2007 by Marc, Oliver, and Alexander Samwer (the "Samwer brothers") who had successfully founded several Internet companies and then invested in firms such as Facebook, LinkedIn, and Zynga. Headquartered in Berlin and operating with local offices worldwide, Rocket Internet has launched more than 100 companies, focusing particularly on underserved or untapped markets in Latin America, South East Asia, India, China, Africa, and the Middle East. According to information provided by the firm, Rocket Internet companies currently employ more than 28,000 people worldwide, focusing on four main sectors: food and groceries, fashion, general merchandise, and home and living.

At the end of 2014, Rocket Internet was listed at the Frankfurt stock exchange. Since then, the group has seen both profits and losses, but low levels of transparency and a complicated nexus of legal and investment relations preclude further insight. At the

(c) The Author(s). 2018 Open Access This article is distributed under the terms of the Creative Commons Attribution 4.0 International License (http://creativecommons.org/licenses/by/4.0/), which permits unrestricted use, distribution, and reproduction in any medium, provided you give appropriate credit to the original author(s) and the source, provide a link to the Creative Commons license, and indicate if changes were made. 
end of 2016, the Samwer brothers' Global Founders Capital (GFC) venture capital fund held more than one third of Rocket Internet. Oliver Samwer, the CEO of Rocket Internet, is the key person, who has been described as a structured thinker with a strong focus on details and competition, once referring to himself as "the most aggressive guy on internet on the planet" (as quoted in Butcher 2011).

\section{Founding new ventures: cloning, mixing, and matching}

Rocket Internet applies a systematic process to new venture creation. Rather than looking for existing combinations of entrepreneurs and ideas to invest in, the company "procures" all necessary factors separately, carrying out "assembly" in-house. The first step is the business idea. Also described as a "clone factory," Rocket Internet copies promising business models and adapts them somewhat to local markets (but sometimes even keeps website designs very close to the original). Treating business models as public goods, the firm searches actively for new ideas, all of which are then evaluated.

Human resources, i.e., a team of founders and early employees, denote another crucial factor for a new venture. Having selected a business idea, Rocket Internet staffs a team based on its existing pool of suitable founders, who can start working on the project right away, sometimes even while additional funds for the project are still being secured. The new startup company does not need to worry about attracting further talent or about the administrative burden of the recruitment process. While Rocket Internet may recruit explicitly for a particular new venture, it also keeps its own pipeline filled, so as to supply a steady stream of talent to its portfolio companies. In recruiting new employees, the firm values aggressiveness, a detail-oriented and data-driven mindset, and a focus on execution. Rather than targeting "typical" entrepreneurs who prefer to have many degrees of freedom to turn their ideas into reality, the firm focuses on ambitious business school graduates that might otherwise seek a career in consulting or investment banking. These graduates are attracted by Rocket Internet's track record and wealth of resources, and are willing to accept less discretion and higher levels of control in return for the career prospects that the firm is offering them.

Financial resources denote a third important building block for a new venture. Backed by the GFC, Rocket Internet has funds at its disposal, which can be allocated to new projects. Once a promising concept has been selected, the firm typically also scans the market for potential co-investors. In addition, startup companies are provided with further resources, so as to allow the founders to focus on building the new business, while Rocket Internet takes care of everything else. Off-the-shelf legal entities for new companies and existing contacts with lawyers facilitate initial administrative processes, while a campus environment provides office space and associated infrastructure. Moreover, new ventures can also make use of existing IT assets (e.g., systems for e-commerce, customer relationship management, online marketing and tracking tools) that can be tailored to their needs, allowing the ventures to set up their operations quickly.

\section{Growing new ventures: scaling up rapidly}

Another remarkable aspect is the pace at which new ventures are grown. As the CEO of the food delivery service HelloFresh illustrated (as quoted in Meyer 2012), it took just 40 days for the service to go live and begin expanding: "We started at the end of 
last year [2011], and we're now active in seven German cities and five countries - the UK, France, the Netherlands and Australia." As discussed above, one factor that enables such "rocket-like" growth is centralized functions that alleviate "distractions" such as recruiting or financing. Another factor is the firm's ability to leverage knowledge and capabilities. Here, hierarchical authority plays an important role, and allegedly it is not uncommon for Rocket Internet executives to intervene with the CEOs of portfolio companies and tell them what to do.

Another advantage of hierarchical structures is the possibility to command knowledge sharing between decentralized units (i.e., portfolio companies), e.g., by codifying knowledge into standard operating procedures. In addition, the fact that Rocket Internet places experienced staff into portfolio companies, and that the firm's managing directors tend to play crucial roles in more than one company at the same time, constitutes important bridges of communication and informal knowledge transfer. Depending on the current needs of a portfolio company, the involvement of Rocket Internet can range from the loose advice that a venture capital firm might provide, to the in-depth collaboration of a consulting relationship. Similarly, in the early stages of a company, when its employees are typically located at the Rocket Internet campus, people even sit in offices sorted along functions rather than portfolio companies.

\section{Little equity for founders}

Rocket Internet always assumes controlling equity stakes in its portfolio companies, giving equity to the founders rather than vice versa, as is typical for traditional incubators or accelerators. Founding entrepreneurs thus hold unusually small levels of equity in "their" companies (for example, CEOs can expect around 5 to 10\%). Furthermore, vesting schedules grant this equity to founders only over time and subject to the achievement of explicit performance goals.

\section{High-powered incentives and work environment}

Given that founders own only small shares in their companies, the potential upsides from selling their equity do not directly match those of "classical" startup firms. Yet a small share in a big pie can be more attractive than a big share in a small pie, if the company turns out to be successful, and founders are attracted by the experience and resources of Rocket Internet. In addition, founders also receive competitive salaries. Complementing such input-based incentives with control and monitoring, Rocket Internet has earned a reputation as a very data-driven company. The use of elaborate tracking and reporting systems allows insights into the development of portfolio companies as well as internal benchmarking. Accordingly, performance targets at Rocket Internet companies are very demanding, and underperformance is punished, no matter whether regular employees or a company's managing directors are concerned. This downside pressure is further increased by the vesting schedules of equity-if founders are removed from their responsibility early on, they also lose their equity in the company. Butcher (2011) quotes an allegedly leaked email by Oliver Samwer: "i give you all the money to win, i give all the trust, but you come back with unmatched success. If $i$ see that you are wasting my money, that you are not German detail oriented, that you are not fast, that you are not aggressive, that you are not data driven, that you are not 
doing logistics well, upload inventory fast, buying wrong inventory, then $i$ get angry and do like in Russia, where no people leading the company now and i lost a ton of money and the founders lost $50 \%$ of their equity and no salary for 6 months."

\section{Open-ended incubation periods}

Compared to traditional incubators or accelerators that tend to have contractually fixed incubation periods, Rocket Internet's influence over its portfolio companies does not have a set termination date. Instead, Rocket Internet follows a strict economic approach, closely monitoring the performance of each company, to then decide about further engagement or exit. While relationships are thus in principle open-ended, the firm's focus on data rather than people and its strict performance culture might foster the perception of a potentially short-term collaboration.

\section{Similar startup factories}

Similar incubators have been established in the USA, Europe, and other countries such as South Korea or Russia. Referring to themselves as "startup factories," "startup studios," or "company builders," these organizations are somewhat different from Rocket Internet in that their approach is less extreme, more inward-looking and organic, or because they operate on a smaller scale.

\section{Can the ideation and execution of business models be separated?}

By implementing business models using standardized processes, Rocket Internet seeks to be faster and operate at lower risk than a team of independent entrepreneurs. By copying proven business models, however, it also separates the creative process of ideation from the operational process of execution. It is thus fair to say that Rocket Internet applies to entrepreneurship and innovation what has driven economic evolution since the industrial revolution: specialization and division of labor. But can the creation of new ventures really be "industrialized"?

Table 1 compares Rocket Internet's startup factory model with other common approaches to making the process of new venture creation more systematic. It suggests that Rocket Internet's reliance on external business models enables it to reap specialization advantages, because it eliminates the opposing need to create an environment that is also conducive to ideation. At the same time, specialization may also be Rocket Internet's largest liability, because it makes the firm dependent on the availability of appropriate (co-specialized) business models. At this point, the final verdict on Rocket Internet has not been spoken. Will its approach turn out to be a nonviable outlier failing to gain legitimacy? Or will it prove to be a viable, and perhaps more efficient, approach to new venture creation in the twenty-first century?

\section{Boundary conditions for the startup factory}

\section{Carsten Bergenholtz and Lars Frederiksen}

The case study about the German organization Rocket Internet is a fascinating story about a very unusual business. A range of theoretical avenues can be pursued, yet in the following, we focus on issues of industry context and imitation strategy, aiming to identify some boundary conditions for this type of organizational endeavor. 
Table 1 Common approaches to systematic venture creation

\begin{tabular}{|c|c|c|c|c|}
\hline & Startup factories & $\begin{array}{l}\text { Business incubators } \\
\text { and accelerators }\end{array}$ & Corporate spin-outs & $\begin{array}{l}\text { Corporate } \\
\text { entrepreneurship }\end{array}$ \\
\hline Example & Rocket Internet & Y Combinator & Thermo Electron & IBM's EBO system \\
\hline Approach & $\begin{array}{l}\text { Assemble and scale } \\
\text { new startup } \\
\text { companies rapidly }\end{array}$ & $\begin{array}{l}\text { Nurture a selected set } \\
\text { of startup companies }\end{array}$ & $\begin{array}{l}\text { Spin out new } \\
\text { businesses into } \\
\text { stand-alone companies }\end{array}$ & $\begin{array}{l}\text { Conceive, develop, } \\
\text { and integrate new } \\
\text { businesses internally }\end{array}$ \\
\hline $\begin{array}{l}\text { Ideation and } \\
\text { execution }\end{array}$ & $\begin{array}{l}\text { External business } \\
\text { model is cloned and } \\
\text { executed by newly } \\
\text { assembled team }\end{array}$ & $\begin{array}{l}\text { Business model is } \\
\text { developed and } \\
\text { executed by } \\
\text { founding teams }\end{array}$ & $\begin{array}{l}\text { Business model is } \\
\text { developed and } \\
\text { executed by } \\
\text { spun-out team }\end{array}$ & $\begin{array}{l}\text { Business model } \\
\text { is developed and } \\
\text { executed by internal } \\
\text { team }\end{array}$ \\
\hline $\begin{array}{l}\text { Parent-venture } \\
\text { relationship }\end{array}$ & $\begin{array}{l}\text { Stand-alone } \\
\text { companies with } \\
\text { strong parental } \\
\text { control and } \\
\text { knowledge sharing }\end{array}$ & $\begin{array}{l}\text { Stand-alone } \\
\text { companies with little } \\
\text { parental control and } \\
\text { some knowledge } \\
\text { sharing }\end{array}$ & $\begin{array}{l}\text { Stand-alone companies } \\
\text { with medium parental } \\
\text { control and knowledge } \\
\text { sharing }\end{array}$ & $\begin{array}{l}\text { Integrated } \\
\text { businesses with } \\
\text { strong parental } \\
\text { control and } \\
\text { knowledge sharing }\end{array}$ \\
\hline $\begin{array}{l}\text { Main advantage } \\
\text { and disadvantage }\end{array}$ & $\begin{array}{l}\text { Allows specialization } \\
\text { on execution, but } \\
\text { depends on supply } \\
\text { of external ideas }\end{array}$ & $\begin{array}{l}\text { Fosters ideation } \\
\text { processes, but does } \\
\text { not support } \\
\text { execution }\end{array}$ & $\begin{array}{l}\text { Combines corporate } \\
\text { and startup } \\
\text { environment, } \\
\text { but is neither fully } \\
\text { one nor the other }\end{array}$ & $\begin{array}{l}\text { Can leverage all } \\
\text { corporate assets, } \\
\text { but businesses are } \\
\text { dependent on } \\
\text { parent }\end{array}$ \\
\hline
\end{tabular}

Rocket Internet is an organization that grows by starting new corporate ventures, which the mother firm runs with strict hierarchical control. This is a type of mass production of startups where key strategic and tactical decisions normally made by the organizational founder and her team are set by the startup factory. A key feature of Rocket Internet is that the business works by cloning existing ideas and business concepts. March (1991) argued that any organization faces the challenge of balancing the trade-off between exploitation and exploration, two concepts that refer to fundamentally different types of activities. Now, an entrepreneurial company that continuously manages to launch and scale new business ideas is usually considered to have managed to successfully succeed in both domains, exploration and exploitation. However, here we have a business model where the focus is on searching for proven ideas with the aim of imitating these ideas and generating a result in the short term. The risk involved is not related to creating a new, and hitherto unproven, business model, but rests upon the ability to select already existing, good ideas. In this sense, Rocket Internet manages to narrow the scope of its exploration-exploitation activities, and avoid some of the typical ambidexterity challenges that every entrepreneurial and scaling organizations usually face.

The question now is within which boundary conditions Rocket Internet is able to circumvent the balance March portrayed. A couple of key features stand out. First of all, visiting the company's web page, we find that it invests in new ventures that are characterized as service-based e-commerce concepts, such as retailing of furniture or clothes, or delivery of take-away food. These ideas are very low-tech and Rocket Internet undertakes no production. Many of the main features of the business models it clones are accessible on an online platform, a visibility that facilitates the imitation process (cf. Posen and Martignoni 2018). This stands in clear contrast to imitating a high-tech service or product, where relevant information will not be as easily accessible.

Based on our interpretation of the case material, we identify at least three related boundary conditions for this type of imitative business model. First, the business concepts to be cloned are of low complexity. The value-creating idea can be detached from context-that is, from the individual, team, or company wherein the original 
"problem-solving" invention and innovation took place. This interdependence allows the business idea to be transferred as well as the application and transfer of core capabilities from one context to the next. Crudely put, physical office facilities have to be set up, the digital platform is established, an online marketing platform is engaged, and KPIs can be set based on similar experiences-all within weeks of the launch. If the business concepts involved higher complexity, such speed would not be feasible.

Second, the businesses cloned are digitalized, which again allows an almost immediate click-and-paste type of imitation. Cloning an offline production site would require a much more intensive information search process, as well as the difficulty of learning about the tacit knowledge such production often entails. In the terms of Hansen (1999), the knowledge to be exchanged is relatively explicit and easy to transfer, further facilitated by key individuals being engaged in multiple ventures.

Third, the businesses imitated are not defined by their high brands. Cloning AirBnB or Amazon would appear to be more difficult, since the value of these services are not just related to a tangible and efficient service, but also the brand value associated with these firms. We will later address if the boundary conditions appear to set tight limits on the long-term sustainability of the overall strategy of Rocket Internet.

Following Posen and Martignoni (2018), it is important to acknowledge that Rocket Internet's main capability is not "merely" to clone. No imitation of a business idea is going to be $100 \%$ accurate (nor should it be according to Posen and Martignoni's (2018) simulations) and a key strength is their ability to aggressively scale their entry into new markets. Relying on the use of ICT, they generate almost real-time performance feedback, which enables a high degree of monitoring of activities, further leading to an extremely fast decision-making process. So, despite the argument often made, ICT in this case seems to favor a type of centralization rather than enable decentralization of the organization. While Rocket Internet appears to be an amalgam of many new ventures, it basically is a hub for knowledge sharing for how to scale up very fast very simple types of business concepts. The company's strategy is that it should be able to see quickly if a concept or the persons involved with the scaling of the ideas in a specific market are not performing according to expectations and thus act upon this information. However, this aggressive scaling also appears to be costly and not without risks, since Rocket Internet suffered a deficit in both 2015 and 2016 (Chazan 2017). Clearly not all ventures it invests in are profitable. Thus, an additional boundary condition for the aggressive scaling strategy that Rocket Internet pursues is the availability of capital at relatively low cost.

In addition to our outline of boundary conditions, we are curious about the case company's ability to engage in such blatant cloning. No intellectual property rights appear to be violated. One would think that their approach could expose them to litigation risks or negative media exposure. Currently, the brand of the company appears positive as they are on an ongoing basis able to recruit talented business school graduates as key employees, offering them relatively high salaries. It should be noted, though, that according to the review site Glassdoor.com, employees do also work very long (80 +) hours, which seems advantageous in the short-term, but might not be sustainable in the long run (Glassdoor review of Rocket Internet 2018).

While Rocket Internet appears to be successful, it is difficult to assess if the company is superior compared to competitors, since it is unclear to what degree there are any of 
the same kind. Furthermore, it is engaged in emergent markets that experience substantial growth. Due to lack of a counterfactual, we do not know if the aggressive attitude of the three founder brothers of the Rocket Internet business is actually useful for improving the organization. That the organizational structure is hierarchical is vital for the fast implementation of business models, while the strong authoritarian leadership style that currently complements it might or might not be a necessary component.

Finally, the case description indicates that a main limitation is the availability of profitable business opportunities. We would argue that due to the continuing growth in emerging markets and the need for smart e-commerce ventures, opportunities will probably abound, even within the given boundary conditions. Nevertheless, time will tell if Rocket Internet will face many more competitors of the same kind, or maybe of a different unified nature, such as Amazon's global approach.

\section{Five critical features of Rocket Internet's business model Robert M. Grant}

Rocket Internet is a strange animal. Although described as a "startup factory," this label does not correspond to any recognizable species. The term "startup factory" has been applied to a number of different types of organization, but most of these appear to be either accelerators or incubators. ${ }^{1}$ Indeed, Rocket Internet seems to be a hybrid of several other species: part corporate incubator, part venture capitalist, part diversified holding company.

In this commentary, I shall identify what I perceive to be the distinctive features of Rocket Internet and discuss their business logic in relation to what I know about strategy and entrepreneurship. I focus on five features of Rocket Internet's business model.

\section{Span of activities}

Baumann and Köhler's case emphasizes the fact that the core feature of Rocket's strategy is the imitation of promising business models. In doing so, it "separates the creative process of ideation from the operational process of execution." This presumes that the founders of ecommerce startups are typically deploying innovative business models. I suggest that most ecommerce startups are also engaged in transfer and adaptation of existing business models. Indeed, my observation about Rocket Internet is the reverse: what strikes me about Rocket is the broad span of activities it undertakes. Compared to a venture capital firm, which is essentially an investment vehicle, or a business incubator which provides support and guidance to entrepreneurs and their startup companies, Rocket is involved in generating business ideas (even though these are based on imitating existing ones), installing entrepreneurial business leaders to establish them, then guiding their development.

This raises questions about the selection process through which promising business models are turned into commercial enterprises. The typical entrepreneurial process through which new businesses are established is a multi-stage selection process. Of the thousands of business proposals that are floated, only a tiny minority emerge as commercial ventures (see Fig. 1). Each stage of funding involves a selection process through which the majority of embryonic ventures are eliminated. Most corporate incubators/ business development units seek to replicate such a process through a phases-and-gates process. At Royal Dutch Shell's Gamechanger unit, only about 1\% of 


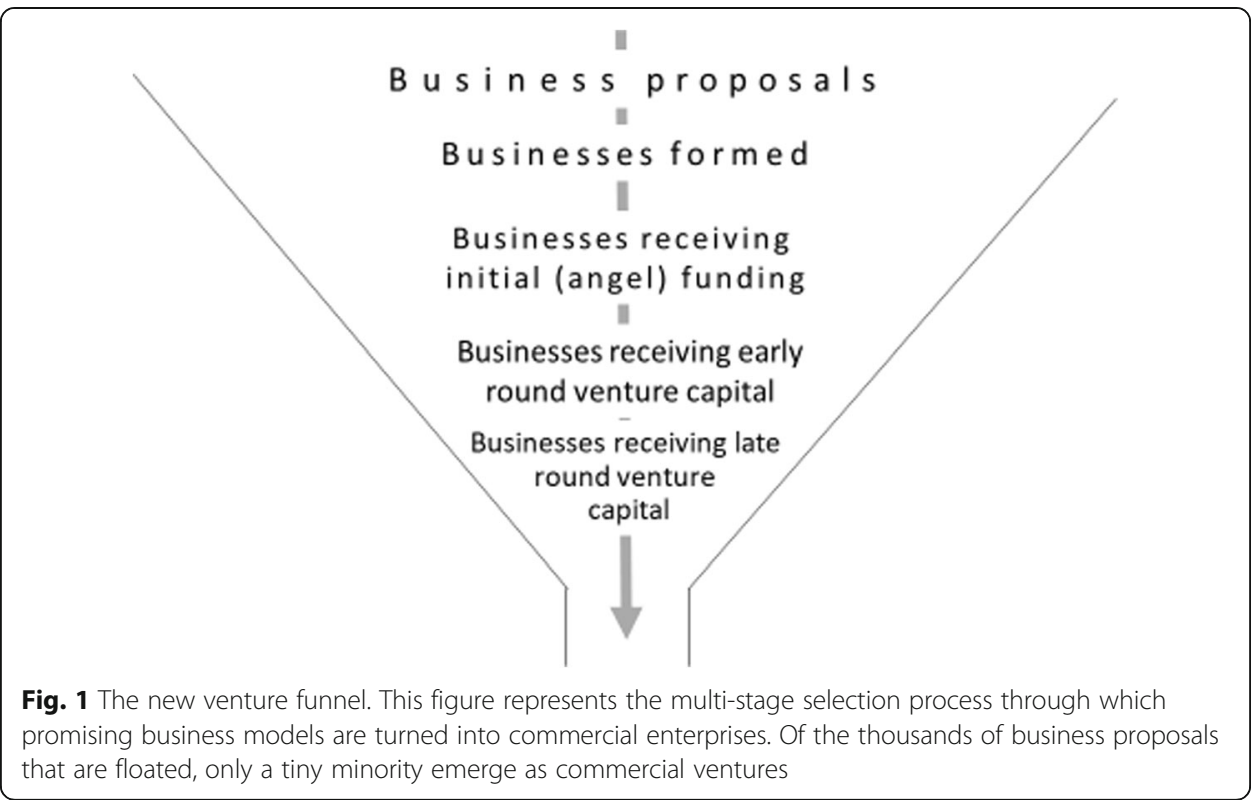

submitted ideas make it through into funded projects (Sloane 2018). The speed of Rocket Internet's business development process and the fact that the decisions over the selection of business ideas and their subsequent funding and development are controlled by the same senior managers may result in a less rigorous selection process that lacks the multiplicity of perspectives inherent in the typical externally financed, new-venture creation process.

\section{Reconceiving the role of entrepreneurs}

Rocket Internet's practice of selecting entrepreneurial projects, then assembling teams to implement them, runs counter to established entrepreneurial practices and principles. Conventional thinking is that entrepreneurship is an individual action of creativity (though, very often, it involves the pairing of a creative leader with a bricoleur who can transfer ideas into practice). The rationale here is that it is founders' passion for and commitment to their business venture that can surmount the many obstacles to business success. Indeed, this principle is embodied in most intrapreneurial practices, too. As Schon observed: "the new idea either finds a champion or it dies" (Schon 1963, p. 84). The internal business development processes of most established companies provide the originators of new product and business ideas with the resources and autonomy to actualize their visions.

Rocket's practice of selecting promising business models, then assigning the development of businesses based on them to a team of existing employees, raises two issues. First, do these teams have the same motivation and tenacity as that shown by successful entrepreneurs such as Ray Kroc at McDonalds, Ingvar Kamprad at IKEA, or Steve Jobs at Apple?

In selecting individuals and teams to lead new businesses, it appears that the backgrounds of Rocket Internet's recruits are predominantly consulting firms, investment banking, and business schools. Yet, evidence on the characteristics of successful 
entrepreneurs identifies prior entrepreneurial experience as an important determinant of the success of a new business (Gompers et al. 2010; Parker 2013; Toft-Kehler et al. 2014).

\section{Rocket's process for developing new businesses}

Rocket's potential for value creation rests upon its ability to apply its systematized business development to a clearly defined set of business opportunities. "We identify and build proven Internet business models and transfer them to new, underserved or untapped markets, mainly outside the United States and China, where we seek to scale them into market leading online companies" (Rocket Internet AG 2014: S-2). It then focuses on particular types of businesses, namely online retailing, online marketplaces (including food delivery, real estate, travel, and transport), and fintech (especially payment services in areas underserved by banks). Having identified opportunities, it then applies a fairly standardized development process to turn these opportunities into viable business enterprises.

The viability of this strategy rest on several assumptions:

- The attractiveness of fast replication of successful ecommerce strategies in new markets. There are numerous examples of successful ecommerce imitation strategies - in India, Flipkart imitated Amazon, Ola imitated Uber. However, successful imitation typically requires both speed and deep local knowledge. Rocket has the former but lacks the latter.

- The superiority of Rocket's business development system. Rocket's approach is novel, but is it superior? Entrepreneurial processes, certainly in relation to venture capital financing, and the processes of incubation and acceleration have become subject to dominant process designs. It is not obvious that Rocket's in-house process is superior either to that through which businesses founded by independent entrepreneurs develop through angel and venture capital funding, or the internal processes of corporate incubators (which benefit from deeper internal knowledge).

- Rocket claims important synergies among its different businesses: "Every new company that the Issuer starts accelerates the virtuous circle of synergy creation among our companies. The larger the size of our network of companies, the more significant our opportunity is to benefit from synergies and network effects with respect to our suppliers, solution providers, customers and employees" (Rocket Internet AG 2014: S-3). However, the diversity of Rocket Internet's businesses suggests that such synergies are limited.

\section{Rocket's incentive system}

The CEOs appointed to Rocket Internet's business startups are remunerated by salary and equity stakes in their businesses, yet, although Baumann and Köhler argue that a "small share in a big pie can be more attractive than a big share in a small pie," evidence on entrepreneurial motivation points to the creative achievement rather than financial reward as the most powerful forces that drive founders.

However, Baumann and Köhler report that Rocket also deploys other incentive mechanisms: it has "elaborate tracking and reporting systems ... as well as internal benchmarking" on the basis of which "performance targets ... are very demanding, and 
underperformance is punished." How effective is such short-term performance tracking? Establishing performance metrics for new businesses is notoriously difficult and, if a new business is failing to meet its targets, it is unclear how the fury and draconian penalties imposed by Rocket Internet on the business head will address the underlying problem.

\section{Legitimacy}

Numerous studies point to the importance of legitimacy in new venture success. Rocket Internet is likely to suffer for two types of legitimacy handicap. First, its approach to new venture development is unorthodox and it is unable to confer the same degree of legitimacy on startup businesses as those conferred by established venture capital firms or corporate incubators at renowned companies such as IBM and Google (now Alphabet). Second, its strategy of imitation has attracted ferocious criticism-not least from the companies that are being imitated.

My conclusion: Rocket Internet is an organizational mutation that is not well suited to the intensely competitive environment of ecommerce. I do not foresee it providing a business model that will be replicated more generally.

\section{A low-risk approach to new venture creation}

\section{David L. Preston}

Rocket Internet is a fascinating and brilliant adaptation of a high-risk tolerance Silicon Valley model to a relatively low-risk tolerance Northern European culture. The Rocket Internet model copies innovations (primarily) coming out of Silicon Valley and adapts them to (primarily) Northern European ecosystems. The inherent genius of this approach is that it reduces the three risks technology investors assess:

1. The technology risk is near zero because presumably the original inventor has proven it out.

2. The market risk is less because presumably the original inventor has successfully commercialized the product or service. Adapting the product to a new market in a new geography still does entail some risk.

3. The team risk is greatly reduced when the Rocket Internet investors hand pick and then micro-manage the new company team.

It is of interest that Baumann and Köhler's introduction mentions that Rocket Internet founders make their money off of Silicon Valley investments. The article does not mention any world-class or worldwide impact firms started by Rocket Internet. A perusal of their web site did not show any firms that were known by this author.

\section{Rocket Internet pros and cons in more detail}

First of all, the model reduces risks as detailed above. It should result in lots of smaller successful new companies and a solid return for Rocket Internet's investors. The model brings new technologies and employment to northern Europe faster than would otherwise happen.

In the longer term, this could create a local experienced entrepreneurial class who then could go on to create really innovative, long-term sustainable, world-class 
successful companies. In this sense, the model can be seen as a logical adaptation to compete with all the advantages that Silicon Valley startups have over Northern European startups.

\section{Cons}

More risk adverse new company heads with relatively small equity positions are probably not as motivated to create Silicon Valley type "unicorns" or billion-dollar valuation companies.

Further, very few fundamentally new technologies will be created when the founding impetus is copying someone else's innovation. That means these firms will probably not have much intellectual property that is defensible.

In the race for global scale, will these local companies always wind up getting acquired (Skype) or passed by when the original inventors who are better motivated focus on the new company's local geography (YouTube, Uber)? What happens to the new company's employment then? Finally, will the best and the brightest individuals with the best ideas continue to relocate to Silicon Valley to execute their new idea (EBay)?

In summary, this is a logical local adaptation to deal with all the myriad advantages that Silicon Valley startup firms have over Northern European startup firms. This should result-and looks like it does-in a good ROI for investors because of the risk reduction involved. If the financial and intellectual capital is reinvested intelligently, this could result in a longer-term flowering of entrepreneurial activity in the region. If the resultant capital is not correctly reinvested, there will be short-term gains for the region and possibly some longer-term disappointment.

\section{Challenging the startup finance model}

\section{Scott Shane}

Has Rocket Internet, the technology company incubator, developed a new model of new business creation or does it represent a dismissible aberration-a failed experiment-in the world of entrepreneurial finance?

We do not yet have the data to answer this question. Therefore, in my commentary on Baumann and Köhler's introduction to Rocket Internet, I will explore the theoretical arguments for this design experiment.

\section{Innovation in organization design}

When most people think of innovation, they think of technological advances, like genetic engineering, the web browser, and autonomous vehicles. But as Schumpeter (1934) clearly explained, that approach is too narrow. Innovation often takes the form of new "ways of organizing."

Throughout history, people have experimented with organization design. The corporation, joint stock company, venture capital fund, corporate venture group, angel group, incubator, and startup accelerator are all examples of innovations that, at one time or another, were developed to improve the new business creation process.

Enterprising individuals experiment with novel ways to organize economic activity in the hopes of coming up with approaches that are more efficient or effective than existing alternatives. When an innovation in organization design proves superior to other 
options, people copy it. When an innovation proves inferior to other options, it gets ignored.

As Baumann and Köhler describe in the introduction, Rocket Internet is an organizational innovation in the world of new company creation. This innovation has five key components: decoupling investor evaluation of venture ideas from evaluation of venture teams, shifting focus from the novelty of business ideas to effectiveness of implementation, deemphasizing fundraising skills, boosting scale economies in business creation, and reducing founder ownership of startup companies. Below, I offer some reasons why the organization might have chosen to undertake this design experiment.

\section{Decoupling the venture idea from the venture team}

Typically, when investors are selecting startup companies to finance, they must choose between different venture ideas developed by different venture teams. That is, the investor decides positively or negatively about the venture team-business idea combination. By hiring a stable of startup company founders, Rocket Internet has decoupled the evaluation of business ideas from the evaluation of founding teams. The organization identifies the business ideas it wants to go after and then tasks its founding teams with pursuing them.

This approach overcomes several problems in the venture creation process. First, in the parlance of venture capitalists, B-quality teams sometimes pursue A-quality venture ideas. Investors often choose not to pursue those excellent venture ideas, preferring lesser ideas pursued by higher quality founding teams. By hiring only A-quality teams and focusing solely on the evaluation of the venture ideas, Rocket Internet ensures that A-quality ideas are pursued by A-quality teams.

Rocket Internet's approach also avoids the problem of needing to reconstitute venture teams. Sometimes, venture teams are uneven, with the CEO, CSO, or CTO being a weak link that needs to be replaced. Other times, teams do not work well together. Rocket Internet's approach resolves these team dynamics problems.

Finally, Rocket Internet's approach allows them to build teams that ensure the right business creation skills, even if people who are good at those activities are weak at the identification and evaluation of new business opportunities.

\section{Shifting the focus to implementation}

Some observers believe that practitioners overweight the importance of the novelty of venture ideas and underweight the value of effective execution. Many successful startups have pursued copycat business ideas. Facebook was not the first social network. Google was not the first Internet search engine. Amazon was not the first online book seller.

Rocket Internet has challenged the notion that having a novel business idea is important to success at business creation. The organization is famous for copying other entrepreneurs' successful business ideas and business models. By repeatedly imitating other entrepreneurs' business models and business ideas, Rocket Internet is showing that the key to startup success lies in executing better on the same idea rather than coming up with an idea that others are not pursuing. 


\section{Little value in fundraising}

Some observers argue that the fundraising process is an effective tool for identifying high potential ventures. But others believe that the process is inefficient, diverting founders' time from creating ventures into unproductive activities. New venture creation, they argue, would be more efficient if raising money were not part of it.

By raising sufficient capital to finance all of its startup opportunities independently of the specific venture ideas it pursues, Rocket Internet has disconnected startup fundraising from the pursuit of business opportunities. In doing so, Rocket Internet is showing that approaches to business creation that are divorced of fundraising are more efficient ways of creating companies than those that rely on financing specific ventures.

\section{Economies of scale in venture creation}

Rocket Internet sought to exploit economies of scale in the legal and administrative activities necessary for new business creation. By creating a standard set of legal entities and human resource structures for its companies, as well as a physical campus where startups can make use of information technology and other assets, Rocket Internet has sought to lower the per venture cost of new company creation. In so doing, the organization has demonstrated that the new venture creation process can be made more efficient by generating multiple new companies simultaneously.

\section{High-powered incentives}

Rocket Internet has challenged the standard assumption that founders of new businesses need to own a large portion of their companies' equity at the beginning of the company creation process. Rocket Internet takes a larger equity stake in startup companies than is typical for most early stage investors. Moreover, it allocates equity to the founders rather than buying it from them. It limits the founding team to smaller amounts of equity than is typical for venture-backed startups, and uses founder vesting to limit conditions where poorly performing founders own much equity in their companies. The success of its approach would run counter to the argument that the success of startups depends on the founders having high-powered incentives.

\section{Conclusion}

We do not have the data to know whether Rocket Internet's approach will be a more efficient way to create new businesses than other, more traditional, approaches. However, a look at the organization's approach suggests that it is a theoretically valid organizational design experiment.

\section{Conclusions}

\section{Oliver Baumann and Rebecca Köhler}

Unlike a regular zoo, the Organization Zoo is populated by many species that were actively designed. Thus, whenever a new organizational animal appears, it is worthwhile to discuss two questions: (1) What are the key design features and possible advantages of this organization? (2) Will the organization prove to be viable or is it only an outlier that will be selected again? In this edition of the Organization Zoo series, we took a closer look at Rocket Internet-the incubator and investment firm that has come to fame for its aggressive approach to cloning existing Internet 
business models and building new ventures in an "industrialized" manner. To help explore Rocket Internet's organization design, we asked several organizational scientists and scholars of entrepreneurship to share their thoughts.

The commentaries by our expert discussants expressed a substantial degree of overlap as to the key features and possible advantages of Rocket Internet's approach. Specifically, they are pointing to potentially reduced levels of risk (for instance, regarding teams and business models), the emphasis on execution (vis-à-vis other aspects of the venturing process such as fundraising), economies of scale, and the positioning in the space of Internet business models that facilitates both imitation and execution processes. As far as the second question is concerned, in contrast, opinions diverged considerably. On one end of the spectrum, Grant is rather pessimistic, pointing to a lack of focus, potential flaws in the selection process for new businesses, as well as the absence of "real," intrinsically motivated entrepreneurs, which leads him to doubt that Rocket Internet is more than a mutation. Bergenholtz and Frederiksen are lukewarm optimistic, seeing some advantages of Rocket Internet's model, if several boundary conditions are fulfilled. Preston takes a broader perspective, pointing to advantages for investors as well as potential longer-term spillover effects of Rocket Internet's activities on the regional startup ecosystems. Finally, Shane is rather unemotional, attesting Rocket Internet the label of a theoretically valid organizational design experiment. In sum, no matter which opinion one is inclined to follow, it is still too early for a final verdict. What can be noted at this point, however, is that the company-builder model appears to remain "en vogue" in the Internet domain, even if it does not usually include imitation as in the case of Rocket Internet. Most major consulting firms, for instance, have started digital offshoots to help their corporate clients build new ventures in an industrialized manner, for example by helping incumbents create their own "digital attackers" (Boston Consulting Group 2018).

In concluding, we note that the commentaries in this article also point to some intriguing broader aspects that may be worth considering when thinking about the prospects of startup factories such as Rocket Internet. One is the underrated value of imitation. While many Silicon Valley firms are (correctly) regarded as highly innovative, most of the big Internet firms such as Amazon, Facebook, and Google were at some point copycats themselves, at least as far as their general business models are concerned, which they often exploited more successfully than their first-mover competitors. Another aspect is the tight coupling between imitation and innovation. That is, if successful imitation is used as a stepping stone toward broader exploration, today's imitators could be tomorrow's innovators, just as Google uses the slack resources it has accumulated in its search and advertising business to fund more risky activities. Alternatively, copycat entrepreneurs might eventually move on to launch truly innovative ventures, thus leveraging their experience in building new companies. Finally, the latter aspect also raises the question of how one should eventually evaluate the performance of Rocket Internet's approach: By looking at the performance of its portfolio companies? By considering how other firms such as corporate incubators are adopting aspects of the startup factory model? Or by asking how Rocket Internet's activities contribute more broadly to the development of an entrepreneurial ecosystem? 


\section{Endnotes}

${ }^{1}$ An accelerator is an organization that provides know-how, capital, and networking opportunities to already established business start-ups, typically over a fixed period of several months, in order to accelerate its development. An incubator is an organization that provides resources and support services to entrepreneurs to help them successfully launch their companies.

Acknowledgements

The authors thank Dorthe Døjbak Håkonsson and Phanish Puranam for helpful comments.

Funding

Not applicable.

\section{Availability of data and materials}

The case of Rocket Internet as depicted in the introduction is drawn entirely from secondary sources and closely follows that of Rebecca Köhler and Oliver Baumann (2015), "Organizing a Venture Factory: Company Builder Incubators and the Case of Rocket Internet." Available at: https://papers.ssrn.com/sol3/papers.cfm?abstract_id=2700098.

\section{Authors' contributions}

Each subsection of the article was written by the author(s) that is (are) listed at the beginning of the respective subsection. OB and RK wrote the "Introduction" section. CB and LF wrote the section "Boundary conditions for the startup factory." RMG wrote the section "Five critical features of Rocket Internet's business model." DLP wrote the section "A low-risk approach to new venture creation." SS wrote the section "Challenging the startup finance model." $\mathrm{OB}$ and RK wrote the "Conclusions" section. All authors read and approved the final manuscript.

\section{Competing interests}

The authors declare that they have no competing interests.

\section{Publisher's Note}

Springer Nature remains neutral with regard to jurisdictional claims in published maps and institutional affiliations.

\section{Author details}

${ }^{1}$ Department of Marketing \& Management, University of Southern Denmark, Campusvej 55, 5230 Odense M, Denmark. ²Department of Management, Aarhus University, Fuglesangs Allé 4, 8210 Aarhus V, Denmark. ${ }^{3}$ Department of Management and Technology, Bocconi University, Via Roentgen 1, 20136 Milan, Italy. ${ }^{4}$ Telefónica Germany Next GmbH, Georg-Brauchle-Ring 50, 80992 Munich, Germany. ${ }^{5}$ Lundquist College of Business - Portland, University of Oregon, 109 NW Naito Parkway, Portland, OR 97209, USA. ${ }^{6}$ Weatherhead School of Management, Case Western Reserve University, 11119 Bellflower Rd, Cleveland, OH 44106, USA.

Received: 6 September 2018 Accepted: 10 October 2018

Published online: 12 November 2018

\section{References}

Boston Consulting Group (2018) Digital transformation https://www.bcg.com/capabilities/technology-digital/digital.aspx Accessed 04 September 2018

Butcher M (2011) In confidential email Samwer describes online furniture strategy as a 'Blitzkrieg'. https://techcrunch.com/ 2011/12/22/in-confidential-email-samwer-describes-online-furniture-strategy-as-a-blitzkrieg/ Accessed 20 Oct 2017

Chazan G (2017) Rocket Internet losses triple in 2016 https://www.ft.com/content/d68c8a2d-982a-335a-9d41-f38ca9a4b735 Accessed 22 May 2018

Glassdoor review of Rocket Internet (2018) https://www.glassdoor.com/Overview/Working-at-Rocket-Internet-El_IE459865. 11,26.htm. Accessed 22 May 2018

Gompers P, Kovner A, Lerner J, Scharfstein D (2010) Performance persistence in entrepreneurship. J Financ Econ 96(1):18-32 Hansen MT (1999) The search-transfer problem: the role of weak ties in sharing knowledge across organization subunits. Admin Sci Q 44(1):82-111

March JG (1991) Exploration and exploitation in organizational learning. Organ Sci 2(1):71-87

Meyer D (2012) A glimpse inside Rocket's copy shop, courtesy of HelloFresh https://gigaom.com/2012/03/01/a-glimpseinside-rockets-copy-shop-courtesy-of-hellofresh/ Accessed 20 October 2017

Parker SC (2013) Do serial entrepreneurs run successively better-performing businesses? J Bus Venturing 28(5):652-666

Posen HE, Martignoni D (2018) Revisiting the imitation assumption: why imitation may increase, rather than decrease, performance heterogeneity. Strateg Manag J 39(5):1350-1369

Rocket Internet AG (2014) Prospectus for the public offering, Berlin

Schon DA (1963) Champions for radical new inventions. Harv Bus Rev 41(2):77-86

Schumpeter J (1934) The theory of economic development. Harvard University Press, Cambridge

Sloane P (2018) Shell gamechanger: The giant still wants big ideas http://innovationexcellence.com/blog/2016/03/16/shellgamechanger-the-giant-still-wants-big-ideas/ Accessed 4 Apr 2018

Toft-Kehler R, Wennberg K, Kim PH (2014) Practice makes perfect: entrepreneurial-experience curves and venture performance. J Bus Venturing 29(4):453-470 